$$
\begin{aligned}
& \text { paper submitted for } \\
& 27 \text { th IECEC, August, } 1992
\end{aligned}
$$

\title{
ACTIVATED TRANSPORT IN AMTEC ELECTRODES
}

\author{
R. M. Williams, B. Jeffries-Nakamura, M. A. Ryan, \\ M. L. Underwood, D. O'Connor, and S. Kikkert \\ Jet Propulsion Laboratory \\ California Institute of Technology \\ Pasadena, CA 91109$$
\text { AIOL- 86CE } 90237
$$

CONF-920801-8

DE92 016810

\section{ABSTRACT}

Transport of alkali metal atoms through porous cathodes of alkali metal thermal-to-electric converter (AMTEC) cells is responsible for significant, reducible losses in the electrical performance of these cells. Experimental evidence for activated transport of metal atoms at grain surfaces and boundaries within some AMTEC electrodes has been derived from temperature dependent studies as well as from analysis of the detailed frequency dependence of ac impedance results for other electrodes, including thin, mature molybdenum electrodes which exhibit transport dominated by free molecular flow of sodium gas at low frequencies or dc conditions. Activated surface transport will almost always exist in parallel with free molecular flow transport, and the process of alkali atom adsorption/desorption from the electrode surface will invariably be part of the transport process, and possibly a dominant part in some cases. Little can be learned about the detailed mass transport process from the ac impedance or current voltage curves of an electrode at one set of operating parameters, because the transport process includes a number of important physical parameters that are not all uniquely determined by one experiment. The temperature dependence of diffusion coefficient of the alkali metal through the electrode in several cases provides an activation energy and pre-exponential, but at least two activated processes may be operative, and the activation parameters should also be expected to depend on the alkali metal activity gradient that the electrode experiences. Variation in the electrode's physical and morphological parameters, by control during deposition and as morphology evolves with electrode aging, may help to distinguish the influence of activated diffusion from adsorption/ desorption, for example. In the case of $\mathrm{Pt} / \mathrm{W} / \mathrm{Mn}$ electrodes operated for 2500 hours, limiting currents varied with electrode thickness, and the activation parameters could be assigned primarily to the surface/grain boundary diffusion process.

\section{INTRODUCTION}

This paper will discuss the microscopic mechanisms which may be operant in electrode kinetics and activated transport; the equivalent circuit description of the physic processes; and finally the specific evidence which can used to evaluate surface diffusion coefficients a chemisorption energies. The interfacial kinetics will also discussed in some detail, as complete resolution of transpr processes from charge transfer processes is not possible AMTEC electrode phenomena.

Transport of alkali metal through the porc electrode on the low pressure side of the beta"-alumina so electrolyte (BASE) is a critical process affecting c performance, because a high pressure drop through 1 electrode significantly reduces the cell's operating volta when current is flowing.[1-3] Several sodium transport mor for different electrodes have been identified or postulate based on experimental results with operating $\mathrm{Na}$ AMTI cells. Electrodes containing molybdenum or tungsten oxic before operation in AMTEC cells initially show excell transport due to ionic conduction of sodium ions throu liquid sodium molybdate or tungstate in the electrod, pores.[4] However, $\mathrm{Na}_{2} \mathrm{MoO}_{4}$ and $\mathrm{Na}_{2} \mathrm{WO}_{4}$ evaporate elevated temperatures. Ionic conduction is also effective Mo/BASE cermet electrodes, but these have not shown hi power densities reproducibly. The dominant $\mathrm{Na}$ transp mechanism in oxide-free $\mathrm{Mo}$ and $\mathrm{W}$ electrodes has be shown to be free molecular flow diffusion, as transport these AMTEC electrodes shows no activation energy temperatures from 1240 down to at least 900 K.[3] Howev another transport process may be dominant in controlling 1 response of these electrodes in the $1 \mathrm{kHz}$ to $10 \mathrm{kHz}$ frequer range. Activated transport via surface diffusion, $\mathrm{gri}$ boundary diffusion, or diffusion of alkali metal though 1 electrode's crystal structure may be important in otl instances.[5] The desorption of an alkali metal atom fron pore wall or from the exterior surface of an AMT] electrode may also be an activated, rate-limiting transp step in some cases. Surface diffusion is a contributi transport mode in Mo electrodes at $\mathrm{kHz}$ frequencies, shown by the Warburg-like frequency response in a impedance measurements. [3] Free molecular flow transp can be calculated to be so rapid through films with the pr 


\section{DISCLAIMER}

This report was prepared as an account of work sponsored by an agency of the United States Government. Neither the United States Government nor any agency Thereof, nor any of their employees, makes any warranty, express or implied, or assumes any legal liability or responsibility for the accuracy, completeness, or usefulness of any information, apparatus, product, or process disclosed, or represents that its use would not infringe privately owned rights. Reference herein to any specific commercial product, process, or service by trade name, trademark, manufacturer, or otherwise does not necessarily constitute or imply its endorsement, recommendation, or favoring by the United States Government or any agency thereof. The views and opinions of authors expressed herein do not necessarily state or reflect those of the United States Government or any agency thereof. 


\section{DISCLAIMER}

Portions of this document may be illegible in electronic image products. Images are produced from the best available original document. 
structure of thin Mo electrodes that it would give rise to a purely resistive response below $\mathrm{MHz}$ frequencies. $[3,6]$

Surface diffusion is also likely to provide the dominant $\mathrm{Na}$ transport pathway in $\mathrm{W} / \mathrm{Pt}$ and $\mathrm{W} / \mathrm{Rh}$ electrodes, which show little open pore area but bave excellent $\mathrm{Na}$ transport properties at AMTEC operating temperatures from 1100-1200 K.[5] In Na vapor exposure cells, W/Rh and W/Pt electrodes on BASE substrates show activated $\mathrm{Na}$ transport, determined from anodic limiting currents, over temperature from 700-1100 K. [7] Experiments run for $>1000$ hours with W/Pt electrodes have been strongly contaminated with $\mathrm{Mn}$ from the steel chamber, heated externally in a furnace, but the resultant electrodes, while not practicable for AMTEC electrodes, have quite good electrochemical characteristics and only slightly increased grain size. This paper will include results from $\mathrm{Pt} / \mathrm{W} / \mathrm{Mn}$ as a model electrode with well defined behavior.

Potassium transport through thin Mo electrodes at lower temperatures (700-900 K) appears to be quite complex mochanistically, while overall kinetics and transport at higher temperatures is very favorable. At the lower temperatures, the current voltage curves are very complex, which is unusual compared with the behavior of sodium at molybdenum electrodes.

These investigations are contributing to optimization of AMTEC electrode performance, involving requirements for long life, efficient mass transport, rapid electrochemical kinetics, and low electrode sheet resistance.

The Mechanistic Model and AC Impedance sections discuss modeling of interfacial kinetics and transport, and are summarized in the Conclusion. New AMTEC experimental results on transport follow the modeling results.

\section{EXPERIMENTAL}

The experimental techniques used in electrode characterization in AMTEC cells, in alkali metal vapor exposure test cells, as well as data reduction techniques have been described previously.[2-4,7-9] Vapor exposure cell experiments utilizing Mo electrodes sputter-deposited on potassium beta"alumina solid electrolyte (K-BASE), and W/Pt or W/Rh electrodes deposited on sodium beta"-alumina (NaBASE) were used to obtain most of the temperature dependent data reported here. Standard expressions for alkali metal vapor pressures were used.[10,11].

\section{RESULTS AND DISCUSSION}

\section{The Mechanistic Model: Kinetics}

The microscopic model for kinetics and transport in AMTEC eloctrodes requires understanding of the dependence of electrode operation parameters on electrode and interface morphology, as well as experimental characterization of these parameters with respect to temperature and other variables. This model contains significant simplifications which may be readily apparent, but it begins to put AMTEC electrode mechanistic phenomena at an molecular level on a more quantitative level.

Measurements performed on mature thin $(0.5 \mu \mathrm{m}) \mathrm{Mo}$ and $(1.0-1.5 \mu \mathrm{m}) \mathrm{W} / \mathrm{Rh}$ and $\mathrm{W} / \mathrm{Pt}$ electrodes have show fairly consistent exchange currents which are proportional t collision rates of $\mathrm{Na}$ gas at the interface over several hundre K.[3] The transfer coefficient, $\alpha$, is always determined to $t$ close to 0.5 for high quality impedance data on matu electrodes at high temperatures, $T>1100 \mathrm{~K}$, and $n$ systematic deviation from this value is observed on coolin although the scatter in derived values increases substantiall: This argues for a simple, one-step, symmetric reaction $f_{i}$ $\mathrm{Na}^{+}+\mathrm{e}^{-} \rightarrow \mathrm{Na}$. The exchange currents of the thin $\mathrm{M}$ electrodes decrease somewhat over several hundred hours about $1200 \mathrm{~K}$ as the grain size increases, and $t$ $\mathrm{Mo} / \mathrm{BASE} / \mathrm{Na}_{\mathrm{G}}$ contact zone decreases in magnitude. $F_{1}$ these high performance electrodes, using data for grain siz void area, and approximate electrode grain/BASE conta angle, the length of the three-phase boundary, $L_{3}$, estimated to be $3-6 \times 10^{4} \mathrm{~cm}$ per $\mathrm{cm}^{2}$ of project geometric electrode area, $A_{\text {GEOM. }}$. At zero net current flor approximately one out of each 500 to 2000 collisions whir would occur at a hypothetical planar surface with ar $A_{\text {GEOM }}$ results in a reaction to produce sodium ions in t] BASE and electrons in the porous metal electrode. Express another way, a $1.0 \mathrm{~cm}^{2}$ electrode has an area of $0.002 \mathrm{cr}$ where a sodium atom from the gas phase will be oxidiz $50 \%$ of the time it collides; and a sodium ion reaching $t$ ] surface will be reduced $50 \%$ of the time also, at op circuit. If the entire three phase zone were electrochemical active, it would need to be only $-0.5 \mathrm{~nm}$ wide. This may $n$ be too great a rate to be caused by simple collisions a electron tunnelling near the three-phase boundar Alternatively, reactants may be rapidly transported to $t$ three phase boundary, or the reaction zone may be greater extent than an atomically narrow zone at the juncture of $t$ BASE with the porous metal and the gas phase. Estimates the macroscopic fractional reactive surface area of a BA! ceramic surface, $F_{E D G E}$ range from $5 \%$ to $30 \%$ of the to BASE surface area, $A_{B A S E}$, which is several times $A_{G E}$ because the ceramic has a bumpy, irregular surface. The estimates are based on low temperature surface decorati experiments, and scanning electron microscopy, for $F_{\text {DDGE }}$ a $A_{\text {BASE }}$, respectively.[3]

Of crystal surfaces containing defect plane edges, 1 thickness $t_{\mathrm{DEF}}$ of the defect planes themselves is a fraction total which also includes spinel block edges with thicknt $t_{\text {SPIN }}$. Spinel block edges are not expected to capture/evol sodium atoms. The fractional microscopic reactive $B A:$ surface area of the projected surface area, $F_{R C T}$, is estimat

$$
\begin{aligned}
& F_{R C T}=F_{E D G E} \times A_{B A S E} \times t_{D E F} /\left[A_{G E O M} \times\left(t_{D E F}+t_{S P I N}\right)\right] \\
& F_{R C T}=0.013 \text { to } 0.16
\end{aligned}
$$

The corresponding length of the three phase bound: crossing defect plane edges is in the range of 0.04 to $1 . C$ $10^{4} \mathrm{~cm}$. The reaction probability, $\mathrm{P}$, for electron tunnelli to a sodium ion at distance $a$ in a defect plane edge described using as a model a simple rectangular poten 1 barrier with a height equal to the electrode's work functis $=2.5 \mathrm{eV}=4.00 \times 10^{-19} \mathrm{~J}$, for a Mo or W alloy electr covered with a partial monolayer of $\mathrm{Na}$; The electro 
energy is $E_{\circ}$; and the total barrier height is $V=E_{0}+\downarrow$. The electron mass is $m_{0}=9.11 \times 10^{-31} \mathrm{~kg}$; and Planck's constant $\mathrm{h}=6.626 \times 10^{-34} \mathrm{~J}-\mathrm{s}$. The probability $\mathrm{P}$ is given in Eq.2a: [12]

$$
P=16 E_{0}\left(V-E_{\lrcorner}\right) V^{-2} \exp \left[-4 r a\left(2 m_{0}\right)^{h / h}\right]
$$

If we take $T=1000 \mathrm{~K}$ for convenience, the energy of the tunnelling electron is $E_{0}=\mathrm{kT}=1.38 \times 10^{-20} \mathrm{~J}$, where $\mathrm{k}=1.381 \times 10^{-23} \mathrm{~J} / \mathrm{K}$ is Boltzmann's constant; and as a result $\mathrm{V}=\mathrm{E}_{\bullet}+\approx=4.14 \times 10^{-19} \mathrm{~J}$.

$P=0.515\left(\exp \left[-4 \pi a\left(2 m_{\varepsilon} s\right)^{1 / 2} / h\right]\right)$

Tunnelling probabilities at $\mathbf{a}=0.5,1.0,2.0,3.0$, and 4.0nm are $P=1.7 \times 10^{-4}, 1.3 \times 10^{-8}, 5.7 \times 10^{-15}, 1.5 \times 10^{-22}$, and $3.3 \times 10^{-20}$, respectively. Because the density of valence level electrons and available empty states in the metal is very high, and the $\mathrm{Na}^{+}$ion density in BASE is also fairly high, these probabilities along with the reactant/product densities and the observed lack of significant activation energy strongly support the tunneling model and suggest the BASE defect block edge as the reaction site, although they also suggest that the reaction occurs primarily quite close $(<1 \mathrm{~nm})$ to the three phase contact "line".

Calculation of a reaction rate from Eq. 2 a requires that some estimate of the densities of initial and final states involved and the attempt frequency be included. The value of the reaction rate is taken to be the product of the surface concentration of $\mathrm{Na}^{+}$; an absolute attempt frequency equal to $\mathrm{kT} / \mathrm{h}$; and the transmission probability, $P$, given above.[13]

$k=d\left(\mathrm{Na}^{+}\right) \times(\mathrm{kT} / \mathrm{h}) \times\left(.515\left(\exp \left[-4 \pi \mathrm{a}\left(2 \mathrm{~m}_{\bullet}\right)^{1 / 2} / \mathrm{h}\right]\right)\right)$

where $d\left(\mathrm{Na}^{+}\right)$is the density of accessible $\mathrm{Na}+$ ions at a distance a from the emitting electrode surface, where the density of electrons of appropriate energy capable of tunnelling is $\mathrm{d}(\mathrm{e})$. At $1000 \mathrm{~K}, \mathrm{kT} / \mathrm{h}$ is equal to

$2.084 \times 10^{13} \mathrm{~s}^{-1}$. If for example we wish to calculate the reaction rate of sodium ions between .70 and $.90 \mathrm{~nm}$ from the three phase line, with electrons between 0.55 and $0.65 \mathrm{~nm}$ above the three phase line, $L_{3}$, assuming an approximate contact angle of electrode with base of $90^{\circ}$, an estimate of the density of $\mathrm{Na}^{+}$ions, $\mathrm{d}\left(\mathrm{Na}^{+}\right)$, is required. The electron density, $\mathrm{d}(\mathrm{e})$, is estimated from the density of $\mathrm{Na}$ atoms adsorbed on the electrode surface, but does not enter the rate equation. The length, $L_{3}$, was calculated above to be 3 to 6 $x 10^{4} \mathrm{~cm} / \mathrm{cm}^{2}$, which multiplied by a height of $1 \mathrm{~nm}$, and a surface density of $13.4 \mathrm{~nm}^{-2}$ for a monolayer of $\mathrm{Na}$ atoms, gives a density at this height in a $1 \mathrm{~cm}^{2}$ electrode of:

$d(e)=4.0$ to $8.0 \times 10^{11}$

From $L_{3}$, the boundary crossing defect plane edges, $\mathrm{d}\left(\mathrm{Na}^{+}\right)$ at .7 to $.9 \mathrm{~nm}$, in a $1 \mathrm{~cm}^{2}$ electrode is calculated in Eq.5, and the resulting rate and current density in Eq.6a and $6 \mathrm{~b}$ :

$d\left(\mathrm{Na}^{+}\right)=0.04$ to $1.0 \times 10^{11}$ atoms $/ \mathrm{cm}^{2}$

$k=0.11$ to $2.7 \times 10^{20}$ atoms $/\left(\mathrm{m}^{2}-\mathrm{s}\right)$ or: j= 1.8 to 43 Amps $/ \mathrm{m}^{2}$

A similar calculation for $\mathrm{a}=.4$ to $.6 \mathrm{~nm}$ give contributions to the reaction rate of $k=.14$ to $3.5 \times 10^{\circ}$ atoms $/ \mathrm{m}^{2}$, and to the exchange current of $\mathrm{j}=.23$ to $5.6 \times 1 \mathrm{C}$ Amps $/ \mathrm{m}^{2}$ an increase of nearly $10^{4}$. These estimates may b somewhat misleading: the first only "counts" one segment $c$ the electrode wall and most of the $\mathrm{Na}^{+}$ions will be reduce by the nearest section of the electrode; the calculated ral was too small; the second ignores the other losses in th process which may impede ion resupply to a small favore reaction area element. However, these calculations show th: observed exchange currents in real electrodes, typically abor $1 \times 10^{5} \mathrm{Amps} / \mathrm{m}^{2}$, are quite consistent with calculations of th reaction rates and exchange currents based on known, imprecise, electrode and electrolyte properties. Tr calculations also show the steepness in dropoff of reactio rate away from the hypothetical three phase line. It possible that there may be a minimum approach distance, $\mathrm{c}$ the order of perhaps 0.2 to $0.5 \mathrm{~nm}$, which occurs in th actual system. However it is also possible that sor asymmetry exists for this reaction even though not reflecte in an clear deviation of the transfer coefficient, $a$, from value of 0.5 . Reduction of $\mathrm{Na}^{+}$may occur under th electrode grains to some extent, and while $\mathrm{Na}^{+}$would $\mathrm{t}$ expected to be absent, or strongly bound on BASE surfact away from the defect block, $\mathrm{Na}$ atoms may diffuse on BAS to the reaction zone.

There is, of course, a weak temperature depende: increase in the collision frequency of $\mathrm{Na}$ gas with tl interface and presumably, $\mathrm{Na}^{+}$ion arrival rates at ts reaction zone in the BASE, which can be considered as thermally activated attempt rate, as well as the we: temperature dependence of the tunnelling probability due the increases in $E_{e}$ with temperature.

A somewhat fuzzy experimental upper limit on tl extent of the reaction zone can also be established, since t] sintering of thin Mo electrodes at $-1200 \mathrm{~K}$ leads eventually a drop in the observed exchange current after the Mo gra size has reached approximately 0.6 to $1.0 \mu \mathrm{m}$ and holes the Mo film of 1.0 to $5.0 \mu \mathrm{m}$ appear. Therefore we $\mathrm{c}$ expect that the upper limit of the extent of the reaction $z 0$ is less than $1.0 \mu \mathrm{m}$ and the lower limit is on the order about $1.0 \mathrm{~nm}$. The upper limit distances are beyond $t$ expected range of electron tunnelling, although a hoppi mechanism could be used to explain a long range $e^{-} / \mathrm{Na}^{+} / \mathrm{S}$ reaction if it is ever observed. However, for completene alternative mechanisms will be briefly discussed. Oth potential mechanisms involve thermionic emission electrons from the metal surface followed by $\mathrm{Na}^{+}$ion capt of electrons which "stick" to the BASE surface; or $\mathrm{Na}^{+}$i evaporation from the BASE surface to the metal. Gas pha reaction of $\mathrm{Na}^{+}$ions with electrons supplied by thermior emission or tunnelling need only be considered if $\mathrm{Na}^{+}$i evaporation has a high rate. The Richardson equation 1 thermionic emission is:[14]

$j_{e}=A T \exp (-/ k T)$

(Eq.

$A$ is a constant and $j_{c}$ is the emission current 
Amp $/ \mathrm{cm}^{2}$.The value of the exponential term at $1000 \mathrm{~K}$ is $2.6 \times 10^{-13}$, so that unless $A$ is exceedingly large, thermionic emission, while not completely negligible in magnitude, would give rise to a electrochemical rate which would be strongly activated, and smaller in magnitude than tunneling.

Similarly, the rate, or flux, of escape of $\mathrm{Na}^{+}$ions from the BASE surface, $\mathrm{k}_{\mathrm{Ne}^{+}}{ }^{+}$, or $\mathrm{j}_{\mathrm{Ne}}{ }^{+}$, is expected to be a strongly activated process, and the equilibrium vapor pressure of $\mathrm{Na}^{+}$ions above BASE at typical AMTEC operating temperatures will be low.

$$
\begin{aligned}
& \mathrm{k}_{\mathrm{Na}}{ }^{+} \leq\left(\mathrm{F}_{\mathrm{RCT}}\right)\left[\mathrm{d}\left(\mathrm{Na}^{+}\right)\right](\mathrm{kT} / \mathrm{h})\left[\exp \left(-\mathrm{E}_{\mathrm{l}} / \mathrm{kT}\right)\right] \\
& \mathrm{k}_{\mathrm{Na}}{ }^{+} \leq .17 \text { to } 2.1 \times 10^{14} \text { atoms } / \mathrm{cm}^{2}-\mathrm{s} \\
& \mathrm{j}_{\mathrm{Na}}{ }^{+} \leq .27 \text { to } 3.4 \times 10^{-4} \mathrm{Amps} / \mathrm{m}^{2}
\end{aligned}
$$

The first two terms in this expression give the total number of $\mathrm{Na}^{+}$ions on the BASE surface; the third term is the absolute evaporation attempt frequency at $\mathrm{T}=1000 \mathrm{~K}$.[13] The exponential gives the probability of the energy of $\mathrm{Na}^{+}$ions necessary for vaporization from the BASE surface, $E_{1} 2.64 \mathrm{eV}$, which is approximately the ionization potential of a free $\mathrm{Na}$ atom, IP $=5.139 \mathrm{eV}$, minus the work function, $\because=2.5 \mathrm{eV}$, because there is no electron produced in the gas phase. Additional activation energy may be involved, but clearly the ion evaporation step is highly temperature dependent and activated, in spite of the favorable supply of $\mathrm{Na}^{+}$ions on the BASE surface; any mechanism requiring evaporation of $\mathrm{Na}^{+}$ions cannot account for the large exchange currents observed at AMTEC electrode.

\section{The Mechanistic Model: Transport}

The transport mechanism when surface or grain boundary activated transport occurs will be quite complex. In nearly all cases, some level of gas phase transport will occur in parallel with, for example, surface diffusion, and adsorption/ desorption will connect the two transport modes. Adsorption may be a necessary step at the interfacial region if, as we suggest, the $\mathrm{Na}$ atom is not produced on the metal surface. Desorption at the exterior surface of the electrode is a necessary step in dc operation of an AMTEC cell. Adsorption and desorption will occur between the parallel gas and surface-confined transport routes, with the net effect of bringing the alkali activity in the gas phase closer to the surface activity. Calculations utilizing reasonable surface diffusion rates and desorption activation energies may be used to estimate how close the activities of surface and gasphase alkali are to equilibrium. Both the surface binding energy and the surface diffusion coefficient are typically strong functions of surface coverage, when coverage is less than one monolayer.

If an isolated electrode grain edge on a BASE surface is considered, for example at the periphery of an electrode, we may do an approximate calculation of the distance an alkali atom will travel on the surface before desorbing. Because this edge effectively borders an infinitely wide pore, the $\mathrm{Na}$ pressure in the gas phase due to Knudsen flow alone will drop precipitously as the interfacial region is left behind. Ideally, the adsorption isotherm, or fractiona! coverage with alkali metal atoms, $\theta$, is known or can be estimated; as well as the rate of evaporation, and the surfact diffusion rate, $D_{s}(\theta)$, as a function of coverage, $\theta$. Som information is available for $\mathrm{Na}$ and $\mathrm{K}$ on $\mathrm{Mo}$ and $\mathrm{K}$ surfaces.[15,16,17] Little of the required information $i$ known about $\mathrm{Na}$ surface adsorbed layers on AMTEC electrodes such as W/Rh or W/Pt. If a Langmuir isotherm i assumed, with adsorption energy independent of coverage coverage drops off exponentially moving away from th interface:

$\mathrm{V}_{\mathrm{D}}=\mathrm{K}_{\mathrm{D}} \oplus \exp \left[-\mathrm{E}_{\mathrm{D}} / \mathrm{RT}\right]$

where $V_{D}$ is the rate of desorption, $K_{D}$ is a constant, and $E$ is the activation energy for desorption. If a Temkin isotherr is assumed as in ref.[3], with estimated binding energ. decreasing with increasing with coverage from $234 \mathrm{~kJ} / \mathrm{mol}$ at zero coverage to $96 \mathrm{~kJ} / \mathrm{mole}$ at full coverage, the rate 0 desorption will fall off more slowly with distance because th binding energy will increase as coverage decreases. $[16,17$ We take $n=n_{s} \theta$,in atoms $\mathrm{cm}^{-2}$ where $n_{s}$ is the tots number of surface sites per unit area are occupied by monolayer of $\mathrm{Na}$, and $n=n_{0}$ at $z=0$, and $D_{s}$ is the surfac diffusion coefficient of $\mathrm{Na}$ on the surface. At a unit are element at a distance $z$ from the interface, the difference $i$ the surface arrival and departure numbers of atoms $D_{s} d^{2} n / d$ i of surface diffusing $\mathrm{Na}$ atoms is equal to the evaporatio rate per unit area, $V_{D}$, expressed in atoms $\mathrm{s}^{-1} \mathrm{~cm}^{-2}$ :

$V_{D}=D_{s} d^{2} n / d z^{2}=n[k T / h] \exp \left[-E_{D} / R T\right]$

where $K_{D} \otimes$ has been replaced in Eq.9 with the density $c$ states, $n$, multiplied by the attempt frequency, kT/h. Eq.1 can be solved to give:

$$
\mathbf{n}(\mathbf{z})=\mathbf{n}_{0} \exp \left\{-\left[k T / h D_{s}\right] \exp \left(\left[-E_{D} / R T\right]^{0.5} z\right)\right\}
$$

Assuming a typical value of $D_{s}=10^{-8} \mathrm{~m}^{2} \mathrm{~s}^{-1}$ and an activatic energy $E_{D}$ of $160 \mathrm{~kJ} / \mathrm{mole}$, at $1000 \mathrm{~K}$, then at $z=0.5 \mu \mathrm{m}$ an $1.0 \mu \mathrm{m}, n$ will equal $.22 n_{0}$ and $.048 n_{0}$, respectively showing that desorption occurs rapidly as the $\mathrm{Na}$ atom movi away from the interface. In a more realistic physical mode the grain wall will bound a crevice, and the gas phas pressure will be more nearly in equilibrium with th absorbed species until the top of the grain is reacher Desorption occurs readily for a typical grain size of $1.0 \mu \mathrm{n}$

\section{AC Impedance Results}

Impedance results on all AMTEC electrodes invariably gi an increasing value of the capacitance as frequency decreas if individual frequency data sets are fit to a parallel $R$ circuit. The calculated capacitance sometimes reaches a near constant value at frequencies around $10 \mathrm{kHz}$, but invariab! rises steeply at low frequencies. The circuit may be fit wi a constant phase element or equivalently with a generaliz: capacitance, but such fits, while helpful in obtaining valu of the resistive components, series inductance, as occasionally the interfacial capacitance when it can 1 
resolved at higher frequencies, do not shed any light on the nature of the capacitive contribution to the transport process. A finite Warburg impedance was anticipated for a surface diffusion transport path, and shown to act as a purely resistive component for free molecular flow gas diffusion at frequencies below $1 \mathrm{MHz}$. Only thin mature Mo electrodes have provided ac impedance data of sufficient quality for resolution of a well defined finite Warburg element, which was somewhat flattened at low frequencies.[3] Good quality $\mathrm{WRh}_{2}$ to $\mathrm{WRh}_{3}$ composition electrodes have shown rather similar features. Resolution of a finite Warburg element after subtraction of series resistance and inductance, followed by subtraction of the parallel interfacial capacitance, and finally the generalized charge-transfer resistance in series with the transport impedance is not alone sufficient to define transport parameters. This is because a finite Warburg impedance in parallel with the resistive network due to free molecular flow diffusion and gas/surface exchange behaves exactly like a finite Warburg with altered characteristics. Initial and terminal resistive processes affect the high frequency series resistance, but under ideal conditions, a physical process described by two parameters for surface diffusion and surface coverage, a adsorption/desorption energy for exchange between gas and surface atoms, a resistance for gas phase diffusion, and initial and final resistances for adsorption and desorption, will give rise to an equivalent circuit characterized fully by only three parameters instead of six. Additional information may be obtained by morphology studies, activation energy determination from temperature variation, and variation in electrode thickness to resolve activated surface transport from adsorption/desorption.

Temperature and Morphology Dependence of Transport of $\mathrm{Na}$ on Mo, WRh, WPtMn; and $K$ on Mo

The transport behavior of $\mathrm{Na}$ on thin, mature Mo electrodes has been most thoroughly studied by ac impedance and current-voltage curves over a wide temperature range, $740 \mathrm{~K}$ to $1240 \mathrm{~K}$, in AMTEC cells with small area electrodes. Typically ac impedance was used with $1 \mathrm{~cm}^{2}$ electrodes and current-voltage curves of 4 to $10 \mathrm{~cm}^{2}$ electrodes were fit with the transfer coefficient constrained at 0.5 to the general kinetics/transport model to give values of the exchange current and a dimensionless transport parameter, G, which could be associated with the electrode's pore structure determined by scanning electron microscopy in the case of electrodes with free molecular flow dominated transport. $[2,3,9] \mathrm{G}$ could be related directly to a diffusion coefficient for $\mathrm{Na}$ gas passing through the electrode, $\mathrm{D}_{\mathrm{Na}}$; neither parameter showed strong temperature dependence, with $G$ about constant and $D_{\mathrm{Ne}}$ decreasing slightly with increasing temperature, consistent with free molecular flow.

Several WRh, electrodes were similarly characterized in AMTEC small electrode cells at temperatures from $900 \mathrm{~K}$ to $1200 \mathrm{~K}$. The values of $D_{N_{a}}$ increased rapidly with temperature at around $1000 \mathrm{~K}$, and the process was somewhat reversible, with slight changes in performance after temperature cycling. $\mathrm{WRh}_{2}$ electrodes were characterized extensively in a sodium exposure test cell (SETC) where a section of BASE tube with several electrodes could be maintained in $\mathrm{Na}$ gas at typical AMTEC operating temperatures for several thousand hours. Limiting current from current voltage curves were used to determine values 0 $D_{\mathrm{Na}_{\mathrm{a}}}$ over a range of electrode temperatures and $\mathrm{Na}$ pressures The diffusion coefficients normalized for thickness wer determined over a range from $725 \mathrm{~K}$ to $1150 \mathrm{~K}$, at $\mathrm{N}$ pressures near $4 \mathrm{~Pa}$ :

$D_{\mathrm{N}}=4.56 \times 10^{-3} \exp [-43.5 \mathrm{~kJ} / \mathrm{RT}] \mathrm{m}^{2} \mathrm{~s}^{-1}$

correcting for the estimated length of the crevice walls i $W h_{2}$ in these electrodes :

$D_{,, N e}=4.56 \times 10^{-7} \exp [-43.5 \mathrm{~kJ} / \mathrm{RT}] \mathrm{m}^{2} \mathrm{~s}^{-1}$

Several SETC experiments were also performed with W/I electrodes; however, the temperature cycling experimen were performed late in test when Mn contamination of thes electrodes had become severe. The temperature dependel transport data for these electrodes probably is representati of $\mathrm{Na}$ transport on $\mathrm{MnPt}$, a dominant phase aft contamination. Electrode performance did not degrac severely however, and $\mathrm{MnPt}$ might be a rather gor electrode for lower temperature applications if the surfa diffusion coefficient of $\mathrm{Mn}$ on the electrode were small. $\mathrm{F}_{\text {I }}$ 1-2.5 $\mu \mathrm{m}$ thick $\mathrm{MnPt} / \mathrm{W}$ electrodes, in approximately $10 \mathrm{l}$ $\mathrm{Na}_{\mathrm{g}}$, the diffusion coefficients normalized for thickness we determined over a range from $765 \mathrm{~K}$ to $1175 \mathrm{~K}$ :

$D_{N_{s}}=0.855 \exp [-172 \mathrm{~kJ} / \mathrm{RT}] \mathrm{m}^{2} \mathrm{~s}^{-1}$

correcting for the length of the three phase line:

$D_{1}=2.85 \times 10^{-5} \exp [-172 \mathrm{~kJ} / \mathrm{RT}] \mathrm{m}^{2} \mathrm{~s}^{-1}$

In the cases of both $\mathrm{WRh}_{2}$ and $\mathrm{MnPt} / \mathrm{W}$, the surfa diffusion measurements were analyzed for limiting curre data measured at similar ambient $\mathrm{Na}$ vapor pressures, ratk than at constant surface coverage, since the correct isother are not known. Therefore the surface diffusion expressic have not been deconvoluted from adsorption effects.

The electrochemistry of Mo electrodes on potassi $\beta^{*}$-alumina $\left(\mathrm{K}^{+} \mathrm{BASE}\right)$ in a $\mathrm{K}$ vapor atmosphere has a been investigated. Only four-probe conductivity measureme and current-voltage curves were taken after the electrodes matured for about 120 hours at $>1200 \mathrm{~K}$. Current-volt curves did not show well defined limiting currents temperatures from 910 to $1210 \mathrm{~K}$, but lower limits diffusion coefficients for $\mathrm{K}$ within these electrodes could determined from current maxima. There was no system temperature dependence of $D_{k}$; the smallest value measu was $4.78 \times 10-5 \mathrm{~m}^{2} \mathrm{~s}^{-1}$ at $1105 \mathrm{~K}$, and the largest was $1.01 \mathrm{x}$ $4 \mathrm{~m}^{2} \mathrm{~s}^{-1}$ at $1058 \mathrm{~K}$, and intermediate values of $D_{K} \quad w$ measuremed at $909 \mathrm{~K}, 941 \mathrm{~K}, 1106 \mathrm{~K}$, and $1207 \mathrm{~K}$. Th results suggest that porous Mo electrodes on $\mathrm{K}^{+} \mathrm{BASE}$ ir vapor are efficient free molecular flow electrodes compar to the same electrodes on $\mathrm{Na}^{+} \mathrm{BASE}$ in $\mathrm{Na}$ vapor. A para enhancing activated transport mode may exist but does seem to dominate in these electrodes. Current-voltage cur showed a distinct local minimum in slope, $\mathrm{dj} / \mathrm{dV}$, at $\mathrm{OV}$ 
$T<900$, an unusual feature for alkali vapor cell experiments.

\section{CONCLUSIONS}

The temperature dependence of $\mathrm{Na}$ transport in $\mathrm{WRh}^{2}$ AMTEC electrodes first indicated an activated transport mode, and the favorable high temperature $\mathrm{Na}$ transport in $\mathrm{W} / \mathrm{Rh}$ and $\mathrm{W} / \mathrm{Pt}$ electrodes having low porosity electrodes suggested surface diffusion or grain boundary diffusion significantly augmented gas phase diffusion in these electrodes. Given the experimental observation that the interfacial reaction rate is not activated, and can be accounted for by a reaction zone near the three-phase interface line, the most likely mechanism is electron tunnelling from the electrode to a $\mathrm{Na}^{+}$ion at the surface of the beta"-alumina, which involves tunnelling through a barrier equal to the work function of the electrode surface $(-2.5 \mathrm{eV})$ with a barrier thickness of $\leq 1.0 \mathrm{~nm}$. The alkali metal atom is therefore produced on the BASE surface and may travel by gas phase diffusion or chemisorb on the metallic electrode and move by activated surface or grainboundary diffusion. While gas phase diffusion has been found to dominate transport of $\mathrm{Na}$ through thin, mature Mo electrodes, and the observed diffusion coefficient for $\mathrm{Na}$ in these electrodes is not activated, ac impedance measurements have clearly indicated a parallel, slower transport mode which dominates electrode performance at higher frequencies, and may be activated. Alkali metal vapor exposure cell experiments have allowed long term investigations of the electrochemical responses of $\mathrm{WRh}_{2}$ and $\mathrm{W} / \mathrm{Pt} / \mathrm{Mn}$ electrodes in a $\mathrm{Na}$ atmosphere and Mo electrodes on K-BASE in a $\mathrm{K}$ atmosphere. Activation energies which appear to be associated with the transport process were measured for the $\mathrm{WRh}_{2}$ and $\mathrm{W} / \mathrm{Pt} / \mathrm{Mn}$ electrodes. Approximate expressions for surface diffusion rates were obtained from these data with knowledge of electrode morphology. Neither current voltage curves nor ac impedance data taken for a single set of electrode parameters: temperature, thickness, grain size, ambient alkali metal vapor pressure, etc, will allow resolution of all the important mechanistic processes occurring in mass transport coupled to charge transfer. By varying these electrode and operating parameters, more features of the electrodes' mechanisms may be resolved.

\section{ACKNOWLEDGEMENTS}

The research described in this paper was performed by the Jet Propulsion Laboratory, California Institute of Technology, and was supported by the Caltech President's Fund, the National Aeronautics and Space Administration, the, and the Air Force Weapons Laboratory. The authors also thank Dr. Joseph Kummer for describing and deriving the behavior of the isolated electrode edge, as well as suggesting possible $\mathrm{Na}^{+}$ion/electron recombination modes. Any errors in the presentation of the model or the conclusions drawn from it are the authors'.

\section{REFERENCES}

1. N. Weber, Energy Conversion, 14, 1, (1974)
2. R. Williams, M. Loveland, B. Jeffries-Nakamura, M Underwood, C. Bankston, H. Leduc, and J. Kummeı J.Electrochem. Soc., 137, 1709, (1990)

3. R. Williams, B. Jeffries-Nakamura, M. Underwood, C Bankston, and J. Kummer, J. Electrochem. Soc., 137, 171t (1990)

4 R. Williams, B. Wheeler, B. Jeffries-Nakamura, M Loveland, C. Bankston, and T. Cole, Journal of " Electrochemical Society, 135, p. 2738 (1988)

5. R. Williams, B. Jeffries-Nakamura, M. Underwood, I Wheeler, M. Loveland, S. Kikkert, J. Lamb, T. Cole, Kummer, and C. Bankston, J. Electrochem. Soc.,136, 89. (1989)

6. B. Wheeler, R. Williams, B. Jeffries-Nakamura, Lamb, M. Loveland, C. Bankston and T. Cole, J. App Electrochem. ,18, 410 (1988)

7. M. A. Ryan, B. Jeffries-Nakamura, R. Williams, M.J Underwood, D. O'Connor and S. Kikkert, Proceedings of " 26th Intersociety Energy Conversion Engineering Conferenc American Nuclear Society, 5, 463 (1991)

8. M.A. Ryan, B. Jeffries- Nakamura, D. O'Connor, M.] Underwood and R.M. Williams, Proceedings of $u$ Symposium on High Temperature Electrode Materials a) Characterization, D. D. Macdonald and A. C. Khandka editors, The Electrochemical Society, 91-6, p. 115 (1991

9. M.L. Underwood, R.M. Williams, B. Jeffries- Nakamus M.A. Ryan and D. O'Connor, Proceedings of the Symposit on High Temperature Electrode Materials a Characterization, D. D. Macdonald and A. C. Khandk: eds., The Electrochemical Society, 91-6, p. 88 (1991).

10. R. Ditchburn and J. Gilmore, Rev. Mod. Phys., 13, 3 (1941)

11. U. Buck and H. Pauly, Z. Phys. Chem., 44, 345 (19t

12. L. I. Schiff, Ouantum Mechanics, $3^{\text {Nd }}$ edition, p 102-1C eq. 17.8, McGraw-Hill Book Co., N.Y.,( 1968)

13. S. Glasstone, K. Laidler, and H. Eyring, Theory of R Processes, McGraw-Hill, New York, (1941)

14. CRC Handbook of Chemistry and Physics, $68^{\text {th }}$ Editic editor in chief, R.C. Weast, pp. F106, E90 CRC Pre Inc.,Boca Raton, FL (1987)

15. R. Morin, Surf. Science, 155, 187, (1985)

16. L. Schmidt and R. Gomer, J. Chem. Phys., 42, (1965)

17. C. Todd and T. Rhodin, Surf. Science, 42,109 (197. 